\title{
Spinocerebellar ataxia: an update
}

\author{
Roisin Sullivan ${ }^{1} \cdot$ Wai Yan Yau ${ }^{1} \cdot$ Emer $^{\prime}$ Connor $^{1} \cdot$ Henry Houlden ${ }^{1}$
}

Received: 27 July 2018 / Revised: 21 September 2018 / Accepted: 25 September 2018 / Published online: 3 October 2018 (c) The Author(s) 2018

\begin{abstract}
Spinocerebellar ataxia (SCA) is a heterogeneous group of neurodegenerative ataxic disorders with autosomal dominant inheritance. We aim to provide an update on the recent clinical and scientific progresses in SCA where numerous novel genes have been identified with next-generation sequencing techniques. The main disease mechanisms of these SCAs include toxic RNA gain-of-function, mitochondrial dysfunction, channelopathies, autophagy and transcription dysregulation. Recent studies have also demonstrated the importance of DNA repair pathways in modifying SCA with CAG expansions. In addition, we summarise the latest technological advances in detecting known and novel repeat expansion in SCA. Finally, we discuss the roles of antisense oligonucleotides and RNA-based therapy as potential treatments.
\end{abstract}

Keywords Spinocerebellar ataxia $\cdot$ Molecular diagnosis $\cdot$ Next-generation sequencing

\section{Introduction}

The Spinocerebellar ataxias (SCA) are a subset of hereditary cerebellar ataxias that are autosomal dominantly transmitted. They are progressive neurodegenerative diseases that share the clinical features of ataxia, which arise from the progressive degeneration of the cerebellum but can also affect other connected regions, including the brain stem. They are a highly heterogenous group of disorders with a complex genotype-phenotype spectrum; many SCAs are caused by CAG nucleotide repeat expansions that encode polyglutamine, and therefore, involve the toxic polyglutamine protein (polyQ) (Fig. 1) [1]. Recent advances in next-generation sequencing have identified new genes implicated in SCAs providing insights into disease transmission and pathogenesis. Here, we discuss updates in epidemiology, clinical features, molecular mechanisms and their potential implications in the future.

Electronic supplementary material The online version of this article (https://doi.org/10.1007/s00415-018-9076-4) contains supplementary material, which is available to authorized users.

Roisin Sullivan

r.sullivan@ucl.ac.uk

1 Department of Neuromuscular Diseases, UCL Queen's

Square Institute of Neurology, Queen's Square House,

Queen's Square, London WC1N 3BG, UK

\section{What is new in the epidemiology of SCA and its subtypes?}

A recent systemic review shows that the global prevalence of SCA is 3 in 100,000 [2], however, a wide regional variation exists. SCA3 is commonest subtype around the globe [3-5], SCA2 is more prevalent in Cuba than SCA3 whilst SCA7 is the most frequent subtype in Venezuela due to strong founder's effect $[6,7]$. SCA6 is one of the most common ADCA in the North of England, with a global prevalence of 5.2/100,000 [8]. There are various mutations described in SCA, although repeat expansions still account for almost half of SCA diagnosis in European cohort. In 412 undiagnosed autosomal dominant cerebellar ataxia (ADCA) without known repeat expansion, 59 individuals (14.3\%) were found to harbor pathogenic variants [9]. Thirty five of these variants $(8.5 \%)$ belong to channel genes. In contrast, conventional mutations in channel genes are rare in Han Chinese cohort [10]. In another cohort of 194 individuals with undiagnosed ADCA, SCA14 accounts for $6.7 \%$ of the studied population [11]. Other similar studies in Germany, United Kingdom, France, United States, Japan and Taiwan confirm the relative rarity of SCA $8,23,35,36$ and 42 . They are each responsible for less than $1 \%$ of undiagnosed ADCA [12-18] although the advance in diversity genetics will further reveal the frequency of these genes in other populations. 
Fig. 1 Mechanism of polyglutamine protein expansion repeats. a Normal translation of polyglutamine repeat within normal repeat range, producing normal protein transcript and protein folding. b Pathogenic polyglutamine expansion repeat length leads to translation of expanded abnormal PolyQ repeat, which leads to protein misfolding. Misfolded polyQ proteins form aggregates which lead to various cellular process dysfunctions, leading to cell toxicity and degeneration. Poly $Q$ polyglutamine proteins
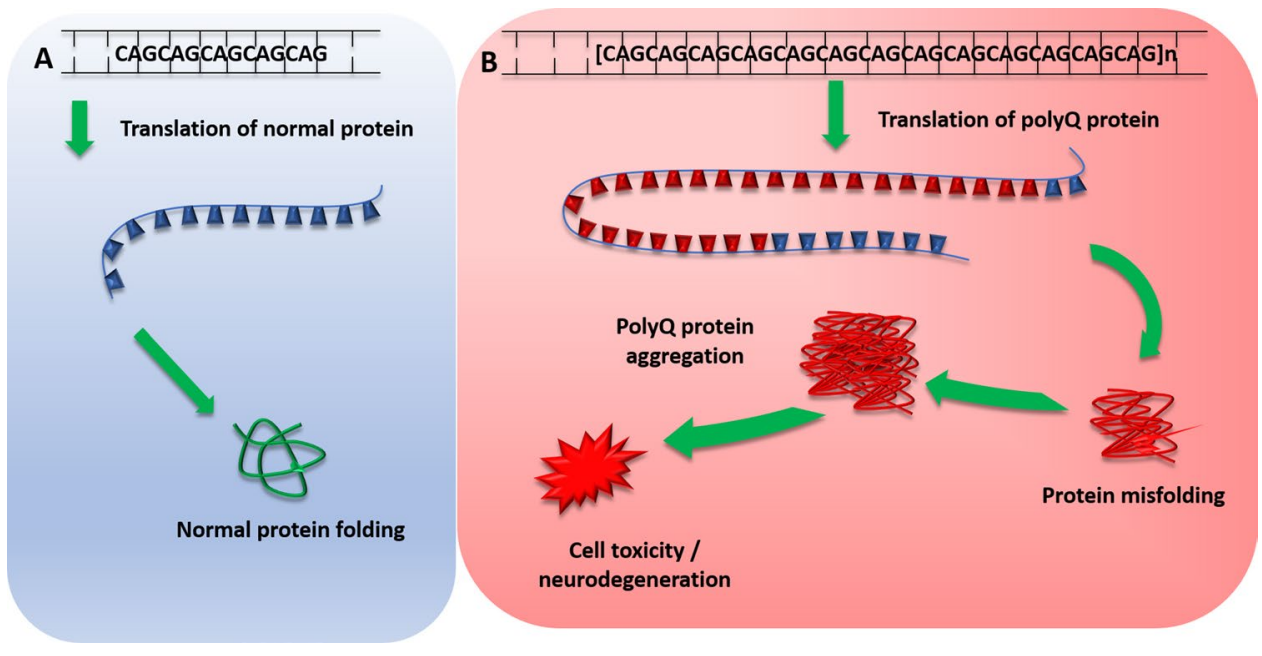

\section{Make sense of SCA clinical features}

The core triad of symptoms of SCAs include gait ataxia and incoordination, nystagmus/visual problems and dysarthria. Patients can present with additional features such as pyramidal, extrapyramidal signs, ophthalmoplegia and cognitive impairment in specific SCAs. Harding's classification of ADCA in 1982 is still useful in the clinical setting (Fig. 2) [19]. ADCA type 1 describes cerebellar ataxia with variable additional signs. This list is ever expanding and includes SCA1-4, 8, 10, 12-14, 15, 17-22, 25, 27, $28,31,32,34-37,38,42-44,46,47$, ataxia with DNMT1 and DRPLA [20-23]. ADCA type 2 describes cerebellar ataxia with pigmentary macular degeneration and consists of only SCA 7 [20]. ADCA type 3 refers to 'pure' cerebellar ataxia, which includes SCA 5, 6, 11, 23, 26, 30, 37,41 and 45 [20, 24]. Several SCAs have characteristic clinical features in addition to cerebellar ataxia and helps distinguish them from other subtypes. For instance, SCA 12,15 and 27 have upper limb postural tremor [25-27]; SCA 14 may have myoclonus and task-specific dystonia [28]; and a subset of SCA 36 have facio-lingual fasciculation with sensorineural hearing loss [29]. Table 1 shows a non-exhaustive list of distinctive clinical signs that feature prominently with cerebellar ataxia, adapted from a recent systematic review [30]. International Parkinson and Movement disorders Task Force recently proposes a new classification of SCA, dividing them into pure or relatively pure ataxia and complex ataxia, which overlaps with above mentioned ADCA classification [31]. A phenotype-first approach remains pertinent in molecular diagnosis of rare
Fig. 2 Harding's classification of Spinocerebellar Ataxia, detailing the classification of SCA based on symptom presentation and the associated SCAs with that classification

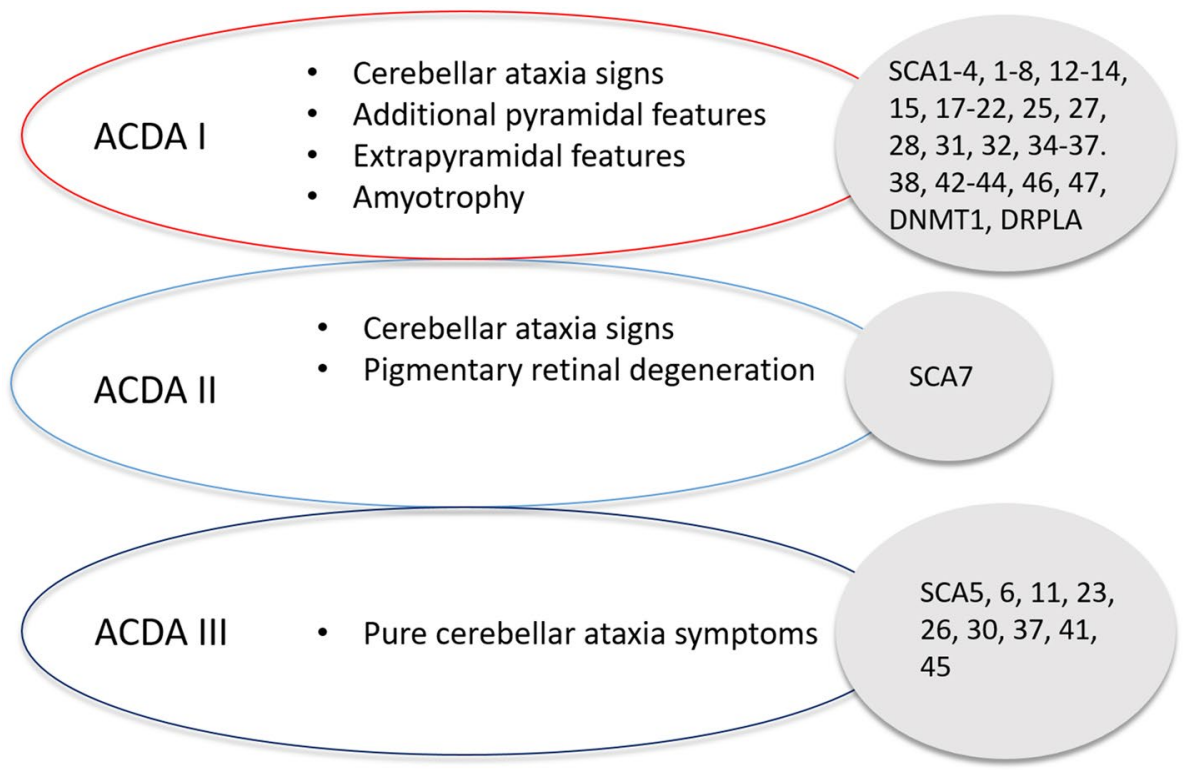


Table 1 SCA subtypes with associated clinical signs that feature prominently with cerebellar ataxia

\begin{tabular}{ll}
\hline Associated clinical features & Genetic subtypes \\
\hline Peripheral neuropathy & $1,2,3,4,18,25,38,43,46$ \\
Pyramidal signs & $1,3,7,8,10,14,15,17,35,40,43$ \\
Dystonia & $3,14,17,20,35$ \\
Myoclonus & 14 \\
Parkinsonism & $2,3,10,14,17,19 / 22,21$ \\
Tremor & $12,15,27$ \\
Chorea & 17,27, DRPLA \\
Cognitive impairment & $2,8,13,17,19 / 22,21,36,44$, DRPLA \\
Psychiatric symptoms & 2,17 \\
Ophthalmoplegia & $2,3,28,40$ \\
Visual impairment & 7 \\
Face/tongue fasciculation & 36 \\
Ichthyosiform plaques & 34 \\
Seizures & $10,19 / 22$, ATN1 \\
Narcolepsy & DNMT1 \\
Hearing loss & 31,36, DNMT1 \\
\hline
\end{tabular}

ATN1 atrophin 1, mutation responsible for dentatorubral-pallidoluysian atrophy, DNA methyltransferase 1, mutation responsible for ADCA-deafness and narcolepsy

genetic disorders (Fig. 3) [32]. Clinicians should also consider genetic testing for primary episodic ataxias (EA), especially with history of episodic attacks of imbalance, dysarthria, vertigo and/or diplopia lasting hours-days. EAs are autosomal dominant channelopathies and they mostly manifest before age 20 years [33]. They can be associated with other paroxysmal neurological disorders such as migraines, epilepsy and dystonia. Patients with EA type 1 also have interictal myokymia. However, progressive cerebellar ataxia may also occur in a proportion of patients with non-expansion mutations in KCNAl and CACNA1A, especially later in the disease course [34, 35]. Unfortunately, the utility of clinical-genetic classification in SCA is limited by high level of phenotype-genotype overlap.

\section{Advances in molecular diagnoses and disease mechanisms}

Advances in next-generation sequencing (NGS) have facilitated further insights into the molecular causes of SCA. When NGS becomes translated to clinical practise, it has the potential to increase the success of molecular diagnosis for patients currently undiagnosed by standard genetic testing. Recent successes include conventional mutations in CCDC88C, TRPC3, CACNA1G, MME, GRM1, FAT2, PLD3 and PUM1 [23, 24, 36-40] since the last update in this journal in 2015 (see Table 2) [41]. Exome sequencing has an average diagnostic rate of $36 \%$ compared to target resequencing panel of $17 \%$ [42]. Exome sequencing identifies less classical phenotype-genotype correlations and detects new mutations in known cerebellar genes [43]. We outline the roles of toxic RNA gain-of-function, mitochondrial
Fig. 3 Flowchart of diagnosis pathway based on either positive or negative result of each diagnostic test. $-v e-n e g a t i v e$

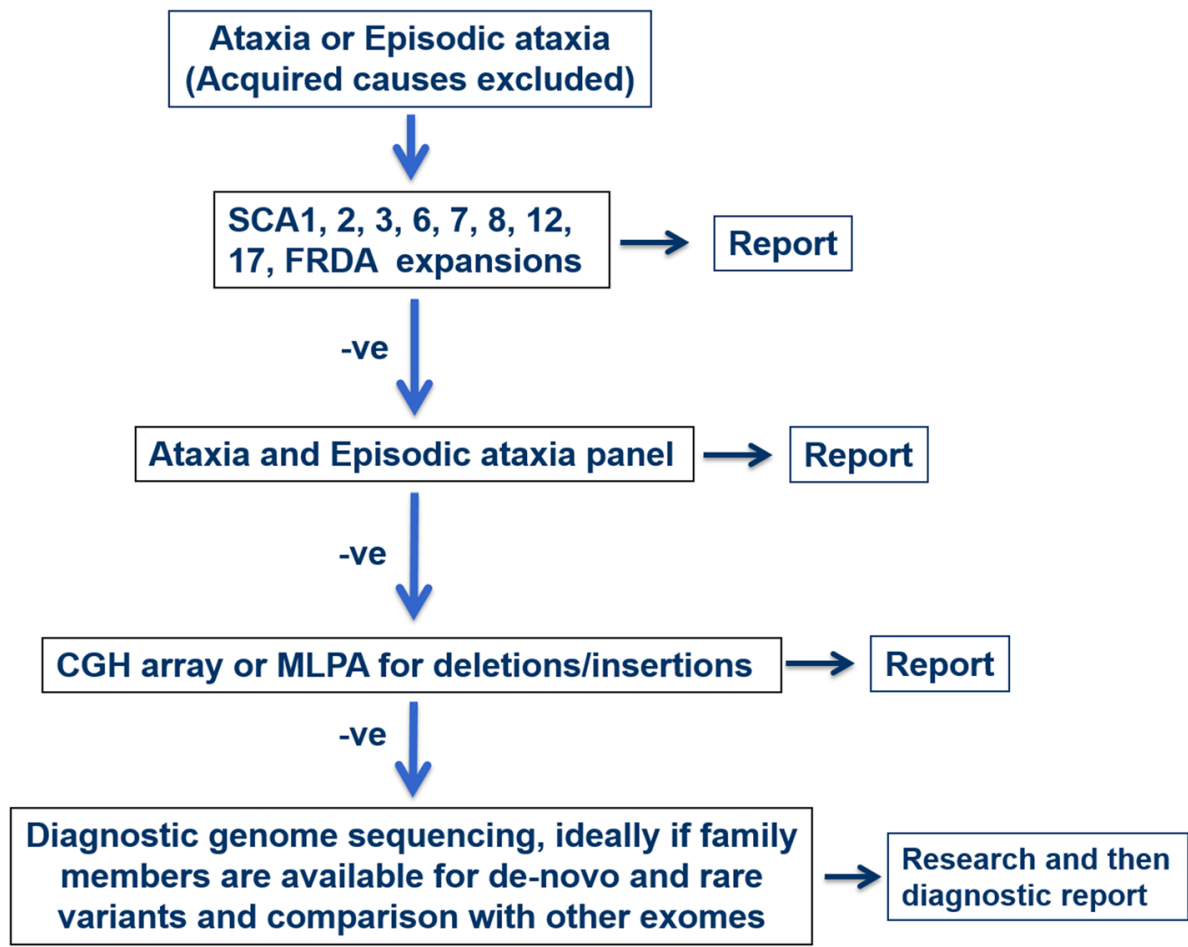


Table 2 Summary of major clinical characteristics of novel SCA genes described since 2015

\begin{tabular}{|c|c|c|c|c|}
\hline Gene/locus & Mutation & Number of pedigrees & Clinical features & Pathogenic mechanisms \\
\hline CCDC88C (SCA 40) [36] & $\begin{array}{l}\text { Missense c. } 1391 \mathrm{G}>\mathrm{A} \\
\quad(\mathrm{pR} 464 \mathrm{H})\end{array}$ & 4 Probands from 1 family & $\begin{array}{l}\text { Cerebellar ataxia, hyper- } \\
\text { reflexia }\end{array}$ & $\begin{array}{l}\text { JNK pathway hyperphos- } \\
\text { phorylation induced } \\
\text { cellular apoptosis }\end{array}$ \\
\hline TRPC3 (SCA 41) [37] & $\begin{array}{l}\text { Missense c. 2285G }>A \\
(p R 762 H)\end{array}$ & 1 Proband from 1 family & Cerebellar ataxia & $\begin{array}{l}\text { Toxic gain-of-function, } \\
\text { channelopathy }\end{array}$ \\
\hline $\begin{array}{l}\text { CACNA1G (SCA 42) [38, } \\
\text { 57] }\end{array}$ & $\begin{array}{l}\text { Missense c.5144G }>A \\
(p R 1715 \mathrm{H})\end{array}$ & $\begin{array}{l}30 \text { Probands from } 5 \\
\text { families }\end{array}$ & Cerebellar ataxia & $\begin{array}{l}\text { Haplo-insufficiency of } \\
\text { T-type calcium channel }\end{array}$ \\
\hline MME (SCA 43) [39] & $\begin{array}{l}\text { Missense c. } 428 \mathrm{G}>\mathrm{A} \\
\quad(\mathrm{p} . \mathrm{C} 143 \mathrm{Y})\end{array}$ & 7 Probands from 1 family & $\begin{array}{l}\text { Cerebellar ataxia with } \\
\text { peripheral neuropathy }\end{array}$ & $\begin{array}{l}\text { Haplo-insufficiency of } \\
\text { neprilysin, a zinc-depend- } \\
\text { ent metalloproteinase }\end{array}$ \\
\hline GRM1 (SCA 44) [40] & $\begin{array}{l}\text { Missense c. } 2375 A>G \\
\quad(p . Y 792 C) \\
\text { c. } 785 A>G(p . Y 262 C)\end{array}$ & 7 Probands from 2 families & $\begin{array}{l}\text { Cerebellar ataxia with } \\
\text { pyramidal sign }\end{array}$ & $\begin{array}{l}\text { Toxic gain-of-function } \\
\text { metabotropic glutamate } \\
\text { receptor } 1\end{array}$ \\
\hline FAT2 (SCA 45) [24] & $\begin{array}{l}\text { Missense c.10946G }>\text { A } \\
\quad(\text { p.R3649Q) } \\
\text { c.10758G }>\text { C (p.K3586N) }\end{array}$ & 6 Probands from 1 family & Cerebellar ataxia & ?affect cell adhesion \\
\hline PLD3 (SCA 46) [24] & $\begin{array}{l}\text { Missense c. } 923 \mathrm{~T}>\mathrm{C} \\
\quad(\mathrm{L} 308 \mathrm{P})\end{array}$ & 11 Probands from 1 family & $\begin{array}{l}\text { Cerebellar ataxia with } \\
\text { peripheral neuropathy }\end{array}$ & $\begin{array}{l}\text { Haplo-insufficiency of } \\
\text { phospholipase D activity }\end{array}$ \\
\hline PUM1 (SCA 47) [23] & $\begin{array}{l}\text { Missense g. } 31414862 \mathrm{~T}>\mathrm{A} \\
\text { (p.T1035S) }\end{array}$ & 9 Probands from 1 family & Cerebellar ataxia & $\begin{array}{l}\text { Haplo-insufficiency of } \\
\text { PUM1 }\end{array}$ \\
\hline
\end{tabular}

CCDC88C coiled-coil domain containing $88 \mathrm{C}, J N K$ c-Jun N-terminal kinase, TRPC3 transient receptor potential cation channel subfamily C member 3, CACNA1G voltage sensor S4 segment of domain IV in Cav3.1T-type calcium channel protein MME neprilysin, GRM1 glutamate metabotropic receptor 1, FAT2 FAT atypical cadherin 2, PLD3 phospholipase D3, PUM1 RNA-binding protein Pumilio1

defects, channelopathy, autophagy and transcriptional dysregulation in pathogenesis of SCA.

\section{Toxic RNA gain-of-function}

Non-coding repeat expansions are implicated in SCA subtypes that include SCA 8, 10, 12, 31, 36 and 37. The hallmarks are transcribed nuclear accumulations of repeat RNAbinding proteins that can cause RNA toxicity and lead to disease pathogenesis (see Fig. 4) [44]. An intronic ATTCT pentanucleotide repeat expansion in ATXN10 has been found to cause SCA10, with pathogenicity in the range of 800-4500 repeats [45]. Cytoplasmic and nuclear foci form in SCA10 cells and SCA10 transgenic mice brain from degradation-resistant, aggregated AUUCU RNA, which is formed from the splicing out of intron 9 from ATXN10 premRNA. The expanded AUUCU RNA binds to heterogeneous nuclear ribonucleoprotein $\mathrm{K}$ (hnRNPK), a spicing factor, causing its sequestration and loss of function. Ultimately this leads to the mitochondrial accumulation of protein kinase $\mathrm{C}$ $\delta$ (PKC $\delta$ ) and apoptosis of SCA10 cells [46]. An intronic GGCCTG hexanucleotide repeat expansion was found in the gene NOP56 using genome-wide linkage, responsible for SCA 36. Patients' lymphoblastoid cells contain RNA foci, and transcription of MIR1292, a neighbouring miMRA is reduced. These implicate a toxic RNA gain-of-function pathological mechanism in SCA 36 [29]. A toxic gain of function effect was found to be implicated in SCA8 pathogenesis, with the CTG CAG repeat expansion, which is bidirectionally expressed, causing [CUG]n transcript accumulation of ribonuclear inclusions that localise with the RNA binding protein Mbnl1. The downstream effects and alternative splicing contribute to the movement disorder phenotype in a SCA8 mice model [47]. Bidirectional expression of sense [CUG]n and antisense [CAG]n has been found in other disorders such as at the DM1 locus [48] and in HDL2, which also forms ribonuclease inclusions [49]. Most recently an unstable intronic ATTTC repeat has been identified as the pathogenic cause of SCA37 in two Spanish cohorts, dysregulating reelin adaptor protein disabled-1 coding $D A B 1$ expression, leading to alternative splicing, an RNA switch and an upregulation of reelin-DAB1 signalling in the SCA37 cerebellum [50].

\section{Mitochondrial dysfunction}

Recently advances have been made in the understanding of mitochondrial dysfunction and ataxia, with several genes related to mitochondrial function identified. These include mutations in OPA1, a mitochondrial dynamin-like GTPase and POLG [9], coding for the catalytic subunit of mitochondrial DNA polymerase gamma, as well as MTATP6 [22]; both of which involve mitochondrial dysfunction. Functional mitochondria are required for all cell processes including cell proliferation, differentiation, apoptotic cell death and are a crucial part of signalling cascades [51]. Findings have 
Fig. 4 Mechanism of RNA foci formation and effects. a Pathogenic SCA intronic and exonic expansion repeats; $\mathbf{b}$ transcription of expanded repeat into expanded mRNA/pre-RNA; c binding of regulatory binding proteins (RBP) to abnormal mRNA transcript; d RBP protein sequestration and abnormal transcript aggregation; e effects of RBP sequestration on cellular processes. $R B P$ regulatory binding proteins, $R A N$ repeat-associated non-ATG

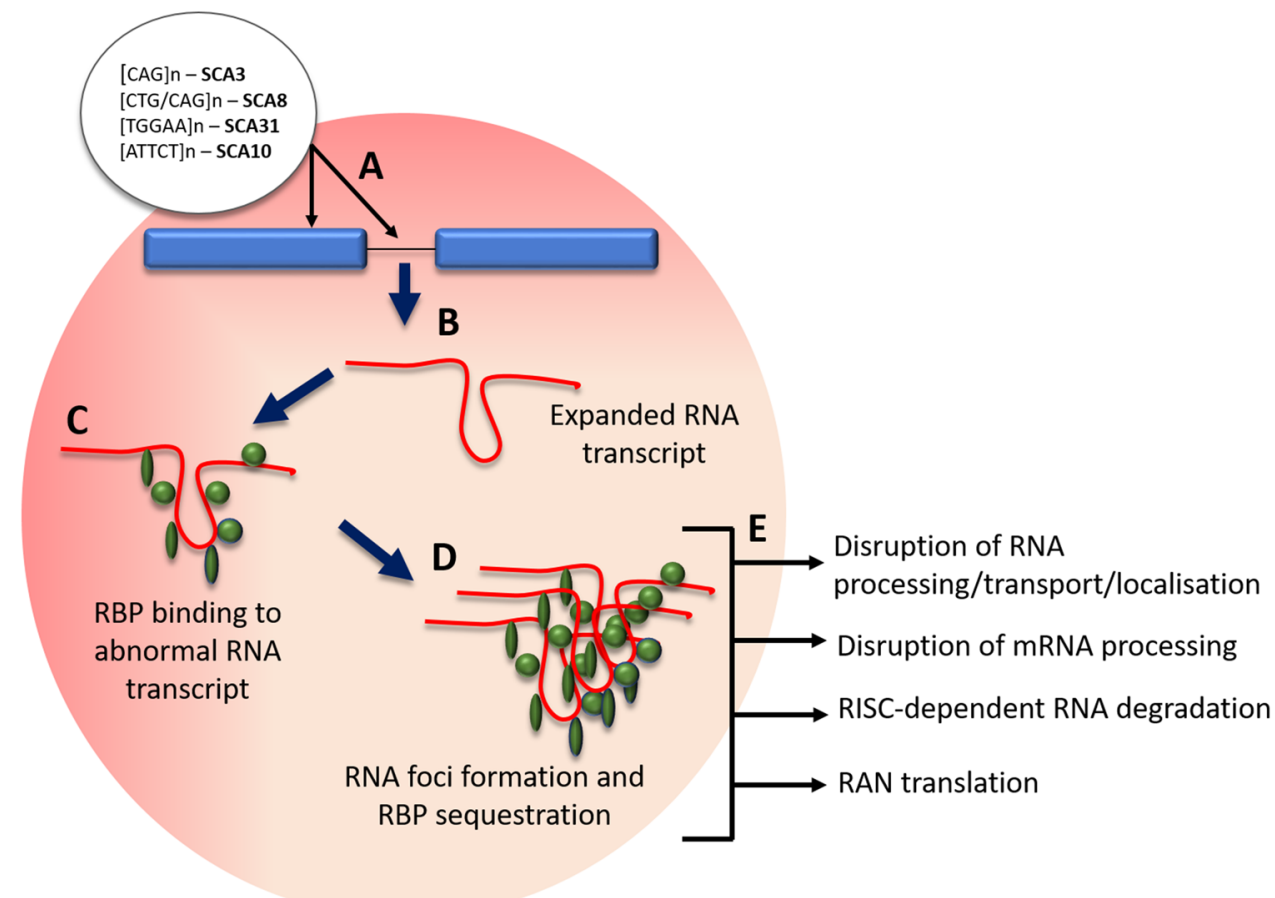

suggested that mitochondrial dysfunction and reactive oxygen species (ROS) may be implicated in SCA2 pathogenesis, with an increase in mitochondrial oxidative stress in SCA2 patient fibroblasts, as well as changes in mitochondrial respiratory chain (MRC) enzymes and in mitochondrial morphology. Importantly these effects were increased in a SCA2 fibroblast line with an expanded CAG repeat from a patient yet to exhibit clinical symptoms, suggesting that mitochondrial dysfunction may precede disease onset. Furthermore, the antioxidant coenzyme Q10 (CoQ10) was found to improve oxidative stress in fibroblasts [52]. Oxidative damage is a frequent feature of neurodegenerative conditions, including Alzheimer's disease and Parkinson's disease, due to the brains high oxygen utilisation and high content of oxidisable polyunsaturated fatty acids [53]. The polymorphic locus A100398G has been implicated in early age of onset in Cuban SCA2 patients [54] and has recently been described in a more severe cognitive phenotype in a 42 SCA2 cohort, corroborating with prior findings in the Cuban cohort [55].

\section{Channelopathies}

Mutations coding for ion channel subunits or regulatory proteins, channelopathies, are frequently involved in the pathology of SCAs. Inherited channelopathies can alter ion channel function by mechanisms including inhibiting the ion movement through an open channel pore and altering ion channel gating through changes to channel opening processes or inactivation processes [56]. A recent study using amplicon-based panel sequencing for 65 genes on 412 index patients found that channelopathies (with mutations in CACNA1A, CACNA1G, KCND3 and KCNC3 in particular) had the earliest age of onset, longest disease duration and slowest disease progression, as well as purest cerebellar presentation. Interestingly they found a prominent implication of SPG7 and CACNA1A in ataxic point mutations [9].

In fact, several newly described SCA gene mutations (GRM1, CACNA1G, TRPC3) are implicated on physiological functions of the cellular channels [37, 38, 40, 57]. Transient receptor potential C3 (TRPC3) mutation occurs in a highly conserved region of the nonselective cation channel and is proposed to affect regulation of channel gating [37]. It has only been described in a sporadic case of adult-onset cerebellar ataxia. Calcium voltage-gated channel subunit alpha $1 \mathrm{G}$ (CACNA1G) mutation leads to altered physiological property in the low voltage-gated calcium channel and causes a relatively pure cerebellar ataxia $[38,57]$. CACNA1G channels are most prominently expressed in Purkinje cells and deep cerebellar nuclei. Electrophysiological study demonstrates that the mutation shifts the current-voltage and the steady-state activation curves of the mutant transfected cells positively [57]. In silico this causes decreased neuronal excitability. Glutamate metabotropic receptor 1 (GRM1) gain-of-function mutations result in excessive glutamate receptor signalling and intracellular calcium level [40]. The authors hypothesised excitotoxicity in cerebellar Purkinje cells as the cause of ADCA in two families. 


\section{Autophagy}

Autophagy is one of the main pathways for degradation of misfolded proteins; the other is the ubiquitin-proteasome system. Autophagy has been linked to neurodegeneration [58]. Both of SCA 3 fibroblast and SCA 7 mouth model demonstrate impaired autophagy $[59,60]$. A mammalian target of rapamycin (mTOR) inhibitor that upregulates autophagy clears ataxin- 3 and aggregates in brain in a SCA 3 mouse model. This appears to slow motor deterioration [61]. Until recently, it remains unclear whether the misfolded protein accumulation causes the dysfunction of autophagy or whether impaired autophagy leads to accumulation of misfolded protein. Ashkenazi et al. demonstrate that widetype ataxin-3 polyglutamine repeat interacts with beclin 1, a key initiator of autophagy [62]. This interaction permits the deubiquitinase activity of ataxin-3 to protect beclin 1 from proteasome-mediated degradation. Thus, it allows autophagy to occur. Long polyglutamine expansion in mutant ataxin-3 competes with wide type ataxin-3 interaction with beclin 1 and leads to impaired starvation-induced autophagy. This highlights the direct role abnormally repeat expansion plays in neurodegeneration of SCA other than protein aggregation.

\section{Transcriptional dysregulation}

The molecular mechanisms of number SCAs (SCA 1, 2, 3, $7,17)$ involve interference with transcription through different mechanisms [63]. These include protein-DNA interactions, acetylation, phosphorylation and RNA interference. The mutant protein Ataxin-1, involved in SCA1 pathogenesis, is a transcription activator, whilst the polyglutamine expansion of SCA 17 occurs within the TATA box-binding protein (TBP), an essential transcription factor [64, 65]. A recently described mutation in RNA-binding protein Pumilio (PUM1) results in ADCA, coined SCA 47 [23]. Experiments in patients' fibroblasts demonstrated that PUM1 protein acts as atranscription repressor. Reduced expression of PUM1 suppresses dendritic arborization. Interestingly, the phenotypic severity of PUM1 mutation varies with the degree which the missense mutations/deletion reduce PUM1 protein levels. Around 50\% reduction of PUM1 protein leads to a severe syndromic development delay whilst $25 \%$ reduction produces adult-onset cerebellar ataxia.

\section{Genetic modifiers}

The clinical diversity of the hereditary cerebellar ataxias in terms of age of onset, progression and severity of disease, strongly suggests the presence of modifying factors. We are beginning to dissect the complex mechanisms of genetic modifiers through the delineation of molecular pathways in the era of high-throughput sequencing. Common genetic variants, with a significant effect size, may act as genetic modifiers in rare mendelian conditions such as SCAs. A Genome-Wide Association Studies (GWAS) on Huntington Disease (HD), a (CAG)n expansion disorder, identified three significant loci with enrichment in DNA repair networks [66]. Subsequently, genotyping of these single nucleotide polymorphisms (SNPs) in 1462 subjects with CAG repeat SCAs and HD showed a significant association between DNA repair genes and the age at onset of SCAs and HD, with SNPs in FAN1 and PMS2 reaching the lowest $p$ values [67]. FAN1 is a repair nuclease that is recruited to sites of crosslink damage and PMS2 endonuclease is a mismatch repair (MMR) protein $[68,69]$. In another association study of 137 parent-child transmissions in SCA 3, a variant ERCC6 (Cockayne syndrome protein CSB) is associated with an expansion bias of (CAG)n [70]. Tight DNA repair regulation is an integral process to maintain integrity of expansions in replication and translation [71]. Dysregulation of DNA repair genes is postulated to result in somatic expansions in non-expanding cells of SCAs with trinucleotide repeat expansions and subsequent disease progression. An International GWAS of repeat expansion ataxia will be extremely valuable to provide further insights into the genetic factors influencing the clinical characteristics of these disorders.

\section{Advances in diagnosis of repeat expansion disorders}

The vast heterogeneity of SCA highlights the effectiveness of whole-exome and -genome sequencing (WES/WGS) as a diagnostic tool. Multiple reads are required for SCAs with conventional disease-causing mutations including singlenucleotide polymorphisms (SNPs), deletions and insertions, to span the full length of the nonreference allele [72]. Currently, high-throughput sequencing technologies are limited to read lengths of approximately 150 base pairs (bp), however, pathogenic expansion repeats can span to thousands of bp in size, therefore, being unidentifiable by short-read sequencing technologies.

Repeat primed-PCR and subsequent fragment analysis is widely used to detect repeat expansions, such as the repeat expansion in the C9orf72 locus implicated in both Amyotrophic Lateral Sclerosis (ALS) and Frontotemporal Dementia (FTD). However, these approaches have a frequent risk of misinterpretation due to false positives and negatives because of indels in the repeat flanking regions and variability in diagnostic laboratory protocols [73]. In addition, repeat length size cannot be estimated by these techniques. The current gold standard for estimating repeat length is Southern blotting which requires substantial amounts of 
DNA (approximately $10 \mu \mathrm{g}$ ) and is vulnerable to somatic heterogeneity, reducing the precision of size estimation [74]. A novel method named tethering PCR, has recently been proposed by Cagnoli et al. to identify pathogenic expansions and estimate repeat size in SCA1, 2, 3, 6 and 7, as well as recognise large alleles and repeat interruptions, negating the need to perform a secondary test (i.e. Southern blot) [75].

Long-read sequencing technologies such as the Oxford Nanopore sequencing and PacBio single-molecule real-time (SMRT) facilitate the sequencing of more than $10,000 \mathrm{bp}$ DNA sequence lengths. Nanopore sequencing uses a protein nanopore covalently attached to an adaptor molecule to identify unlabeled nucleoside $5^{\prime}$ monophosphate molecules. It has an average accuracy of $99.8 \%$. It can function without exonuclease and has a high accuracy of not registering the same nucleotide twice due to translocation through the nanopore [76]. By contrast, SMRT sequencing uses real-time imaging of fluorescently tagged nucleotides during DNA synthesis along template models, using DNA polymerase as a reaction driver [77]. PacBio reads have around a 15\% average higher error rate [78], however, Oxford Nanopore platforms also have limitations with their MiniION sequencer having a reported estimated base-calling error rate of $38.2 \%$ [79].

Due to the popularity of WGS, developing a method for pathogenic repeat expansions has been of interest. Recently a software package called ExpansionHunter has been developed by Illumina that can determine the size of repeats of varying size, including very large pathogenic expansions much longer than the read length, using PCR-free WGS data [80]. They developed an algorithm able to identify reads in several different conditions; reads that span the full length, reads that fully contain the repeat ['in-repeat' reads (IRR)] and repeats that include the repeat and flanking sequence on one side of the repeat. The software correctly classified all C9orf72 expanded samples in an ALS cohort as either expanded, possibly expanded or wild-type as well as 8 other pathogenic repeat expansions, including samples from SCA1 and SCA3 cohorts. The tool facilitates the screening of repeat expansions using a single run of WGS, with PCR-free WGS data. Development is still in progress as currently the software requires an STR to be specified by reference coordinate and repeat motif. However, future association studies and available WGS-data will provide a genome-wide STR database, which will greatly enhance the utility of ExpansionHunter.

\section{Future direction and potential treatments}

Advancements in the understanding of pathophysiologic mechanisms facilitate the potential to find new therapeutic targets. Current treatment pipelines involve the use of pharmacological molecules to target affected downstream pathways, as well as genetic therapies to decrease toxic polyQ gene products. The former could benefit a larger proportion of patients if the targeted pathway is implicated in several neurodegenerative diseases, however, if a mutant protein affects multiple cellular processes it could prove difficult to target a vital pathway to provide effective treatment [81].

\section{Antisense oligonucleotides}

Antisense oligonucleotides (ASOs) are small single-stranded sequences of DNA that have the gene-targeting effect of reducing levels of toxic protein or making non-toxic modifications which are valuable tools for neurodegenerative diseases [82]. Successful uptake of ASOs facilitates their gene-modulating effects and relies on effective delivery. Mechanisms include lysosomal or endosomal compartmental internalisation, association with high- and low-binding plasma proteins and cellular trafficking.

ASOs decrease the expression of the target protein using Watson-Crick hybridization to bind to complementary mRNA transcripts and recruit RNase H enzymes [83]. ASO-mediated exon skipping has been successfully applied to SCA3 fibroblasts, removing the central 88 amino acid region of the ataxin-3 protein in one study to halt production of potentially toxic cleavage fragments; however, proteinmodification effect was at a low-level [84, 85]. ASO therapy targeting SCA3 mice models has also been shown to reduce disease protein levels by greater than $50 \%$ in the cerebellum, diencephalon, cervical spinal cord and forebrain, presenting with no signs of microgliosis and astrogliosis, indicating its potential for a well-tolerated preventative therapy despite no observable reduction in motor phenotype [86, 87]. ASO therapy targeting ATXN2 has shown slowed progression of the motor phenotype and improved survival in both SCA2 [81] and ALS transgenic mouse model TDP-43 [88].

\section{RNA based therapy}

Therapeutics based on RNA interface (RNAi) harness the cellular mechanism of gene expression silencing to reduce the expression of pathological proteins. Synthetic small interfering RNA (siRNAs) and short hairpin RNA (shRNAs) control the RNAi process of target mRNA enzymatic cleavage in a predictable and consistent action [89]. RNAi has been successfully used to reduce mutant ataxin-7 in SCA7 mouse models in a nonallele- [90] and allele-specific manner [91]. ATXN3 has also been suppressed in Machado-Joseph disease (MJD) mouse models, with reports of improved motor symptoms and neuropathology $[92,93]$. 


\section{Stem cell based therapy}

Some stem cell-based therapies have been performed on several cerebellar mutant mice, such as SCA1 mouse models [94-98], with reports of normalized motor deficits and reduced Purkinje cell loss and SCA2 models which showed delayed onset of motor function deterioration [99]. Phase I and II clinical trials, one of which involved intravenously infused human umbilical cord mesenchymal stem cell (UC-MSC) into SCA1, 2 or 3 cohorts $(n=16)$ reported no transplantation side effects and an improved International Cooperative Ataxia Rating Scale (ICARS) and Berg Balance Scale (BBS) score after 6 months posttransplantation [100]. Another trial on 14 SCA patients using intrathecal injection of UC-MSC reported significant ICARS and Activity of Daily Living Scale (ADL) scores, which decreased after 1 month of treatment, although 8 patients remained stable for 6-9 months post-transplantation [101]. These suggest a potential proof of principle for stem cell therapy as a therapeutic intervention, however, assessment of efficacy and safety requires further clinical trials.

\section{Conclusions}

Tremendous scientific progress has occurred in the understanding of spinocerebellar ataxia. Next-generation sequencing has helped improve the diagnostic accuracy of SCAs and discover new disease mechanisms. New technologies such as nanopore and ExpansionHunter may help improve diagnosis of known and new SCAs with repeat expansions in future. As outlined, evidence suggests that genes in DNA repair pathways appear to play a modifying role. An international GWAS of repeat expansion ataxia would be worthwhile to pursue these potential therapeutic targets. Meanwhile, emerging therapies for neurogenetic diseases such as ASOs also provide physicians and patients of SCA hopes of effective treatments in the near future.

Acknowledgements This work was funded by the Medical Research Council (R.S), Ataxia UK (W.Y), Rosetrees Trust (W.Y) and Brain Research UK (E.O).

\section{Compliance with ethical standards}

Ethical approval This article does not contain any studies with human participants performed by any of the authors.

Open Access This article is distributed under the terms of the Creative Commons Attribution 4.0 International License (http://creativeco mmons.org/licenses/by/4.0/), which permits unrestricted use, distribution, and reproduction in any medium, provided you give appropriate credit to the original author(s) and the source, provide a link to the Creative Commons license, and indicate if changes were made.

\section{References}

1. Paulson HL, Shakkottai VG, Clark HB, Orr HT (2017) Polyglutamine spinocerebellar ataxias-from genes to potential treatments. Nat Rev Neurosci 18(10):613-626

2. Ruano L, Melo C, Silva MC, Coutinho P (2014) The global epidemiology of hereditary ataxia and spastic paraplegia: a systematic review of prevalence studies. Neuroepidemiology 42(3):174-183

3. de Castilhos RM, Furtado GV, Gheno TC, Schaeffer P, Russo A, Barsottini O et al (2014) Spinocerebellar ataxias in Brazil-frequencies and modulating effects of related genes. Cerebellum 13(1):17-28

4. Coutinho P, Ruano L, Loureiro JL, Cruz VT, Barros J, Tuna A et al (2013) Hereditary ataxia and spastic paraplegia in Portugal: a population-based prevalence study. JAMA Neurol 70(6):746-755

5. Zaltzman R, Sharony R, Klein C, Gordon CR (2016) Spinocerebellar ataxia type 3 in Israel: phenotype and genotype of a Jew Yemenite subpopulation. J Neurol 263(11):2207-2214

6. Gonzalez-Zaldivar Y, Vazquez-Mojena Y, Laffita-Mesa JM, Almaguer-Mederos LE, Rodriguez-Labrada R, Sanchez-Cruz $\mathrm{G}$ et al (2015) Epidemiological, clinical, and molecular characterization of Cuban families with spinocerebellar ataxia type 3/ Machado-Joseph disease. Cerebellum Ataxias 2:1

7. Paradisi I, Ikonomu V, Arias S (2016) Spinocerebellar ataxias in Venezuela: genetic epidemiology and their most likely ethnic descent. J Hum Genet 61(3):215-222

8. Bargiela D, Yu-Wai-Man P, Keogh M, Horvath R, Chinnery PF (2015) Prevalence of neurogenetic disorders in the North of England. Neurology 85(14):1195-1201

9. Coutelier M, Coarelli G, Monin ML, Konop J, Davoine CS, Tesson $\mathrm{C}$ et al (2017) A panel study on patients with dominant cerebellar ataxia highlights the frequency of channelopathies. Brain 140(6):1579-1594

10. Chen Z, Wang P, Wang C, Peng Y, Hou X, Zhou X et al (2018) Updated frequency analysis of spinocerebellar ataxia in China. Brain 141(4):e22

11. Chelban V, Wiethoff S, Fabian-Jessing BK, Haridy NA, Khan A, Efthymiou $\mathrm{S}$ et al. Genotype-phenotype correlations, dystonia and disease progression in spinocerebellar ataxia type 14 . Mov Disord. 2018

12. Aydin G, Dekomien G, Hoffjan S, Gerding WM, Epplen JT, Arning L (2018) Frequency of SCA8, SCA10, SCA12, SCA36, FXTAS and C9orf72 repeat expansions in SCA patients negative for the most common SCA subtypes. BMC Neurol 18(1):3

13. Fawcett K, Mehrabian M, Liu YT, Hamed S, Elahi E, Revesz T et al (2013) The frequency of spinocerebellar ataxia type 23 in a UK population. J Neurol 260(3):856-859

14. Guo YC, Lin JJ, Liao YC, Tsai PC, Lee YC, Soong BW (2014) Spinocerebellar ataxia 35: novel mutations in TGM6 with clinical and genetic characterization. Neurology 83(17):1554-1561

15. Ngo K, Aker M, Petty LE, Chen J, Cavalcanti F, Nelson AB et al (2018) Expanding the global prevalence of spinocerebellar ataxia type 42. Neurol Genet 4(3):e232

16. Obayashi M, Stevanin G, Synofzik M, Monin ML, Duyckaerts C, Sato N et al (2015) Spinocerebellar ataxia type 36 exists in diverse populations and can be caused by a short hexanucleotide GGCCTG repeat expansion. J Neurol Neurosurg Psychiatry 86(9):986-995 
17. Lee YC, Tsai PC, Guo YC, Hsiao CT, Liu GT, Liao YC et al (2016) Spinocerebellar ataxia type 36 in the Han Chinese. Neurol Genet 2(3):e68

18. Valera JM, Diaz T, Petty LE, Quintans B, Yanez Z, Boerwinkle E et al (2017) Prevalence of spinocerebellar ataxia 36 in a US population. Neurol Genet 3(4):e174

19. Harding AE (1982) The clinical features and classification of the late onset autosomal dominant cerebellar ataxias. A study of 11 families, including descendants of the 'the Drew family of Walworth'. Brain 105(Pt 1):1-28

20. Bird TD (1993) Hereditary ataxia overview. In: Adam MP, Ardinger HH, Pagon RA, Wallace SE, Bean LJH, Stephens K et al (eds) GeneReviews((R)). Seattle (WA)

21. Winkelmann J, Lin L, Schormair B, Kornum BR, Faraco J, Plazzi $\mathrm{G}$ et al (2012) Mutations in DNMT1 cause autosomal dominant cerebellar ataxia, deafness and narcolepsy. Hum Mol Genet 21(10):2205-2210

22. Pfeffer G, Blakely EL, Alston CL, Hassani A, Boggild M, Horvath R et al (2012) Adult-onset spinocerebellar ataxia syndromes due to MTATP6 mutations. J Neurol Neurosurg Psychiatry 83(9):883-886

23. Gennarino VA, Palmer EE, McDonell LM, Wang L, Adamski CJ, Koire A et al (2018) A Mild PUM1 mutation is associated with adult-onset ataxia, whereas haploinsufficiency causes developmental delay and seizures. Cell 172(5):924-936 e11

24. Nibbeling EAR, Duarri A, Verschuuren-Bemelmans CC, Fokkens MR, Karjalainen JM, Smeets C et al (2017) Exome sequencing and network analysis identifies shared mechanisms underlying spinocerebellar ataxia. Brain 140(11):2860-2878

25. Holmes SE, O'Hearn EE, McInnis MG, Gorelick-Feldman DA, Kleiderlein JJ, Callahan C et al (1999) Expansion of a novel CAG trinucleotide repeat in the $5^{\prime}$ region of PPP2R2B is associated with SCA12. Nat Genet 23(4):391-392

26. Synofzik M, Beetz C, Bauer C, Bonin M, Sanchez-Ferrero E, Schmitz-Hubsch T et al (2011) Spinocerebellar ataxia type 15: diagnostic assessment, frequency, and phenotypic features. J Med Genet 48(6):407-412

27. van Swieten JC, Brusse E, de Graaf BM, Krieger E, van de Graaf $\mathrm{R}$, de Koning I et al (2003) A mutation in the fibroblast growth factor 14 gene is associated with autosomal dominant cerebellar ataxia [corrected]. Am J Hum Genet 72(1):191-199

28. Chen DH, Brkanac Z, Verlinde CL, Tan XJ, Bylenok L, Nochlin $\mathrm{D}$ et al (2003) Missense mutations in the regulatory domain of PKC gamma: a new mechanism for dominant nonepisodic cerebellar ataxia. Am J Hum Genet 72(4):839-849

29. Kobayashi H, Abe K, Matsuura T, Ikeda Y, Hitomi T, Akechi $Y$ et al (2011) Expansion of intronic GGCCTG hexanucleotide repeat in NOP56 causes SCA36, a type of spinocerebellar ataxia accompanied by motor neuron involvement. Am J Hum Genet 89(1):121-130

30. Rossi M, Perez-Lloret S, Doldan L, Cerquetti D, Balej J, Millar Vernetti P et al (2014) Autosomal dominant cerebellar ataxias: a systematic review of clinical features. Eur J Neurol 21(4):607-615

31. Marras C, Lang A, van de Warrenburg BP, Sue CM, Tabrizi SJ, Bertram L et al (2016) Nomenclature of genetic movement disorders: recommendations of the international Parkinson and movement disorder society task force. Mov Disord 31(4):436-457

32. Pena LDM, Jiang YH, Schoch K, Spillmann RC, Walley N, Stong $\mathrm{N}$ et al (2018) Looking beyond the exome: a phenotype-first approach to molecular diagnostic resolution in rare and undiagnosed diseases. Genet Med 20(4):464-469

33. Jen JC, Graves TD, Hess EJ, Hanna MG, Griggs RC, Baloh RW et al (2007) Primary episodic ataxias: diagnosis, pathogenesis and treatment. Brain 130(Pt 10):2484-2493
34. Graves TD, Cha YH, Hahn AF, Barohn R, Salajegheh MK, Griggs RC et al (2014) Episodic ataxia type 1: clinical characterization, quality of life and genotype-phenotype correlation. Brain 137(Pt 4):1009-1018

35. Jen J, Kim GW, Baloh RW (2004) Clinical spectrum of episodic ataxia type 2. Neurology 62(1):17-22

36. Tsoi H, Yu AC, Chen ZS, Ng NK, Chan AY, Yuen LY et al (2014) A novel missense mutation in CCDC88C activates the JNK pathway and causes a dominant form of spinocerebellar ataxia. J Med Genet 51(9):590-595

37. Fogel BL, Hanson SM, Becker EB (2015) Do mutations in the murine ataxia gene TRPC3 cause cerebellar ataxia in humans? Mov Disord 30(2):284-286

38. Morino H, Matsuda Y, Muguruma K, Miyamoto R, Ohsawa R, Ohtake $\mathrm{T}$ et al (2015) A mutation in the low voltage-gated calcium channel CACNA1G alters the physiological properties of the channel, causing spinocerebellar ataxia. Mol Brain 8:89

39. Depondt C, Donatello S, Rai M, Wang FC, Manto M, Simonis N et al (2016) MME mutation in dominant spinocerebellar ataxia with neuropathy (SCA43). Neurol Genet 2(5):e94

40. Watson LM, Bamber E, Schnekenberg RP, Williams J, Bettencourt C, Lickiss J et al (2017) Dominant mutations in GRM1 cause spinocerebellar ataxia type 44 . Am J Hum Genet 101(3):451-458

41. Coutelier M, Stevanin G, Brice A (2015) Genetic landscape remodelling in spinocerebellar ataxias: the influence of nextgeneration sequencing. J Neurol 262(10):2382-2395

42. Galatolo D, Tessa A, Filla A, Santorelli FM (2018) Clinical application of next generation sequencing in hereditary spinocerebellar ataxia: increasing the diagnostic yield and broadening the ataxia-spasticity spectrum. A retrospective analysis. Neurogenetics 19(1): 1-8

43. Coutelier M, Hammer MB, Stevanin G, Monin ML, Davoine CS, Mochel F et al (2018) Efficacy of exome-targeted capture sequencing to detect mutations in known cerebellar ataxia genes. JAMA Neurol 75(5):591-599

44. Wojciechowska M, Krzyzosiak WJ (2011) Cellular toxicity of expanded RNA repeats: focus on RNA foci. Hum Mol Genet 20(19):3811-3821

45. Lin X, Ashizawa T (2005) Recent progress in spinocerebellar ataxia type-10 (SCA10). Cerebellum 4(1):37-42

46. White M, Xia G, Gao R, Wakamiya M, Sarkar PS, McFarland K et al (2012) Transgenic mice with SCA10 pentanucleotide repeats show motor phenotype and susceptibility to seizure: a toxic RNA gain-of-function model. J Neurosci Res 90(3):706-714

47. Daughters RS, Tuttle DL, Gao W, Ikeda Y, Moseley ML, Ebner $\mathrm{TJ}$ et al (2009) RNA gain-of-function in spinocerebellar ataxia type 8. PLoS Genet 5(8):e1000600

48. Cho DH, Thienes CP, Mahoney SE, Analau E, Filippova GN, Tapscott SJ (2005) Antisense transcription and heterochromatin at the DM1 CTG repeats are constrained by CTCF. Mol Cell 20(3):483-489

49. Rudnicki DD, Holmes SE, Lin MW, Thornton CA, Ross CA, Margolis RL (2007) Huntington's disease-like 2 is associated with CUG repeat-containing RNA foci. Ann Neurol 61(3):272-282

50. Corral-Juan M, Serrano-Munuera C, Rabano A, Cota-Gonzalez D, Segarra-Roca A, Ispierto L et al (2018) Clinical, genetic and neuropathological characterization of spinocerebellar ataxia type 37. Brain 141(7):1981-1997

51. McBride HM, Neuspiel M, Wasiak S (2006) Mitochondria: more than just a powerhouse. Curr Biol 16(14):R551-R560

52. Cornelius N, Wardman JH, Hargreaves IP, Neergheen V, Bie AS, Tumer Z et al (2017) Evidence of oxidative stress and mitochondrial dysfunction in spinocerebellar ataxia type 2 (SCA2) patient 
fibroblasts: effect of coenzyme Q10 supplementation on these parameters. Mitochondrion 34:103-114

53. Valko M, Leibfritz D, Moncol J, Cronin MT, Mazur M, Telser J (2007) Free radicals and antioxidants in normal physiological functions and human disease. Int J Biochem Cell Biol 39(1):44-84

54. Simon DK, Zheng K, Velazquez L, Santos N, Almaguer L, Figueroa KP et al (2007) Mitochondrial complex I gene variant associated with early age at onset in spinocerebellar ataxia type 2. Arch Neurol 64(7):1042-1044

55. Monte TL, Pereira FS, Reckziegel EDR, Augustin MC, LocksCoelho LD, Santos ASP et al (2017) Neurological phenotypes in spinocerebellar ataxia type 2: role of mitochondrial polymorphism A10398G and other risk factors. Parkinsonism Relat Disord 42:54-60

56. Kass RS (2005) The channelopathies: novel insights into molecular and genetic mechanisms of human disease. J Clin Invest 115(8): 1986-1989

57. Coutelier M, Blesneac I, Monteil A, Monin ML, Ando K, Mundwiller E et al (2015) A recurrent mutation in CACNA1G alters Cav3.1 T-type calcium-channel conduction and causes autosomal-dominant cerebellar ataxia. Am J Hum Genet 97(5):726-737

58. Jimenez-Sanchez M, Thomson F, Zavodszky E, Rubinsztein DC (2012) Autophagy and polyglutamine diseases. Prog Neurobiol 97(2):67-82

59. Alves S, Cormier-Dequaire F, Marinello M, Marais T, Muriel MP, Beaumatin F et al (2014) The autophagy/lysosome pathway is impaired in SCA7 patients and SCA7 knock-in mice. Acta Neuropathol 128(5):705-722

60. Onofre I, Mendonca N, Lopes S, Nobre R, de Melo JB, Carreira IM et al (2016) Fibroblasts of Machado Joseph disease patients reveal autophagy impairment. Sci Rep 6:28220

61. Menzies FM, Huebener J, Renna M, Bonin M, Riess O, Rubinsztein DC (2010) Autophagy induction reduces mutant ataxin-3 levels and toxicity in a mouse model of spinocerebellar ataxia type 3. Brain 133(Pt 1):93-104

62. Ashkenazi A, Bento CF, Ricketts T, Vicinanza M, Siddiqi F, Pavel M et al (2017) Polyglutamine tracts regulate beclin 1-dependent autophagy. Nature 545(7652):108-111

63. Matilla-Duenas A, Sanchez I, Corral-Juan M, Davalos A, Alvarez R, Latorre P (2010) Cellular and molecular pathways triggering neurodegeneration in the spinocerebellar ataxias. Cerebellum $9(2): 148-166$

64. Mushegian AR, Bassett DE Jr, Boguski MS, Bork P, Koonin EV (1997) Positionally cloned human disease genes: patterns of evolutionary conservation and functional motifs. Proc Natl Acad Sci USA 94(11):5831-5836

65. Yang S, Li XJ, Li S (2016) Molecular mechanisms underlying Spinocerebellar Ataxia 17 (SCA17) pathogenesis. Rare Dis 4(1):e1223580

66. Genetic Modifiers of Huntington's Disease C (2015) Identification of Genetic Factors that Modify Clinical Onset of Huntington's Disease. Cell 162(3):516-526

67. Bettencourt C, Hensman-Moss D, Flower M, Wiethoff S, Brice A, Goizet $C$ et al (2016) DNA repair pathways underlie a common genetic mechanism modulating onset in polyglutamine diseases. Ann Neurol 79(6):983-990

68. Thongthip S, Bellani M, Gregg SQ, Sridhar S, Conti BA, Chen Y et al (2016) Fan1 deficiency results in DNA interstrand cross-link repair defects, enhanced tissue karyomegaly, and organ dysfunction. Genes Dev 30(6):645-659

69. Trinh TQ, Sinden RR (1991) Preferential DNA secondary structure mutagenesis in the lagging strand of replication in E. coli. Nature 352(6335):544-547

70. Martins S, Pearson CE, Coutinho P, Provost S, Amorim A, Dube MP et al (2014) Modifiers of (CAG)(n) instability in
Machado-Joseph disease (MJD/SCA3) transmissions: an association study with DNA replication, repair and recombination genes. Hum Genet 133(10):1311-1318

71. McMurray CT (2010) Mechanisms of trinucleotide repeat instability during human development. Nat Rev Genet 11(11):786-799

72. Raczy C, Petrovski R, Saunders CT, Chorny I, Kruglyak S, Margulies EH et al (2013) Isaac: ultra-fast whole-genome secondary analysis on Illumina sequencing platforms. Bioinformatics 29(16):2041-2043

73. Akimoto C, Volk AE, van Blitterswijk M, Van den Broeck M, Leblond CS, Lumbroso S et al (2014) A blinded international study on the reliability of genetic testing for GGGGCC-repeat expansions in $\mathrm{C} 9$ orf72 reveals marked differences in results among 14 laboratories. J Med Genet 51(6):419-424

74. Ashley EA (2015) The precision medicine initiative: a new national effort. JAMA 313(21):2119-2120

75. Cagnoli C, Brussino A, Mancini C, Ferrone M, Orsi L, Salmin $P$ et al (2018) Spinocerebellar ataxia tethering PCR: a rapid genetic test for the diagnosis of spinocerebellar ataxia types 1, $2,3,6$, and 7 by PCR and capillary electrophoresis. J Mol Diagn 20(3):289-297

76. Clarke J, Wu HC, Jayasinghe L, Patel A, Reid S, Bayley H (2009) Continuous base identification for single-molecule nanopore DNA sequencing. Nat Nanotechnol 4(4):265-270

77. Roberts RJ, Carneiro MO, Schatz MC (2013) The advantages of SMRT sequencing. Genome Biol 14(7):405

78. Carneiro MO, Russ C, Ross MG, Gabriel SB, Nusbaum C, DePristo MA (2012) Pacific biosciences sequencing technology for genotyping and variation discovery in human data. BMC Genom 13:375

79. Laver T, Harrison J, O’Neill PA, Moore K, Farbos A, Paszkiewicz $\mathrm{K}$ et al (2015) Assessing the performance of the Oxford Nanopore Technologies MinION. Biomol Detect Quantif 3:1-8

80. Dolzhenko E, van Vugt J, Shaw RJ, Bekritsky MA, van Blitterswijk M, Narzisi G et al (2017) Detection of long repeat expansions from PCR-free whole-genome sequence data. Genome Res 27(11):1895-1903

81. Pulst SM (2016) Degenerative ataxias, from genes to therapies: the 2015 Cotzias lecture. Neurology 86(24):2284-2290

82. Schoch KM, Miller TM (2017) Antisense oligonucleotides: translation from mouse models to human neurodegenerative diseases. Neuron 94(6): 1056-1070

83. Geary RS, Norris D, Yu R, Bennett CF (2015) Pharmacokinetics, biodistribution and cell uptake of antisense oligonucleotides. Adv Drug Deliv Rev 87:46-51

84. Toonen LJ, Schmidt I, Luijsterburg MS, van Attikum H, van Roon-Mom WM (2016) Antisense oligonucleotide-mediated exon skipping as a strategy to reduce proteolytic cleavage of ataxin-3. Sci Rep 6:35200

85. Evers MM, Tran HD, Zalachoras I, Pepers BA, Meijer OC, den Dunnen JT et al (2013) Ataxin-3 protein modification as a treatment strategy for spinocerebellar ataxia type 3: removal of the CAG containing exon. Neurobiol Dis 58:49-56

86. Moore LR, Rajpal G, Dillingham IT, Qutob M, Blumenstein KG, Gattis D et al (2017) Evaluation of antisense oligonucleotides Targeting ATXN3 in SCA3 mouse models. Mol Ther Nucleic Acids 7:200-210

87. Toonen LJA, Rigo F, van Attikum H, van Roon-Mom WMC (2017) Antisense oligonucleotide-mediated removal of the polyglutamine repeat in spinocerebellar ataxia type 3 mice. Mol Ther Nucleic Acids 8:232-242

88. Becker LA, Huang B, Bieri G, Ma R, Knowles DA, JafarNejad P et al (2017) Therapeutic reduction of ataxin-2 extends lifespan and reduces pathology in TDP-43 mice. Nature 544(7650):367-371 
89. Bumcrot D, Manoharan M, Koteliansky V, Sah DW (2006) RNAi therapeutics: a potential new class of pharmaceutical drugs. Nat Chem Biol 2(12):711-719

90. Ramachandran PS, Boudreau RL, Schaefer KA, La Spada AR, Davidson BL (2014) Nonallele specific silencing of ataxin-7 improves disease phenotypes in a mouse model of SCA7. Mol Ther 22(9):1635-1642

91. Scholefield J, Greenberg LJ, Weinberg MS, Arbuthnot PB, Abdelgany A, Wood MJ (2009) Design of RNAi hairpins for mutation-specific silencing of ataxin-7 and correction of a SCA7 phenotype. PLoS One 4(9):e7232

92. Nobrega C, Nascimento-Ferreira I, Onofre I, Albuquerque D, Hirai H, Deglon N et al (2013) Silencing mutant ataxin-3 rescues motor deficits and neuropathology in Machado-Joseph disease transgenic mice. PLoS One 8(1):e52396

93. Costa Mdo C, Luna-Cancalon K, Fischer S, Ashraf NS, Ouyang M, Dharia RM et al (2013) Toward RNAi therapy for the polyglutamine disease Machado-Joseph disease. Mol Ther 21(10):1898-1908

94. Weimann JM, Charlton CA, Brazelton TR, Hackman RC, Blau HM (2003) Contribution of transplanted bone marrow cells to Purkinje neurons in human adult brains. Proc Natl Acad Sci USA 100(4):2088-2093

95. Fernandez-Funez P, Nino-Rosales ML, de Gouyon B, She WC, Luchak JM, Martinez P et al (2000) Identification of genes that modify ataxin-1-induced neurodegeneration. Nature 408(6808):101-106

96. Chen KA, Cruz PE, Lanuto DJ, Flotte TR, Borchelt DR, Srivastava A et al (2011) Cellular fusion for gene delivery to SCA1 affected Purkinje neurons. Mol Cell Neurosci 47(1):61-70

97. Chintawar S, Hourez R, Ravella A, Gall D, Orduz D, Rai $M$ et al (2009) Grafting neural precursor cells promotes functional recovery in an SCA1 mouse model. J Neurosci 29(42):13126-13135

98. Alvarez-Dolado M, Pardal R, Garcia-Verdugo JM, Fike JR, Lee HO, Pfeffer K et al (2003) Fusion of bone-marrow-derived cells with Purkinje neurons, cardiomyocytes and hepatocytes. Nature 425(6961):968-973

99. Chang YK, Chen MH, Chiang YH, Chen YF, Ma WH, Tseng CY et al (2011) Mesenchymal stem cell transplantation ameliorates motor function deterioration of spinocerebellar ataxia by rescuing cerebellar Purkinje cells. J Biomed Sci 18:54

100. Jin JL, Liu Z, Lu ZJ, Guan DN, Wang C, Chen ZB et al (2013) Safety and efficacy of umbilical cord mesenchymal stem cell therapy in hereditary spinocerebellar ataxia. Curr Neurovasc Res 10(1):11-20

101. Dongmei H, Jing L, Mei X, Ling Z, Hongmin Y, Zhidong W et al (2011) Clinical analysis of the treatment of spinocerebellar ataxia and multiple system atrophy-cerebellar type with umbilical cord mesenchymal stromal cells. Cytotherapy 13(8):913-917

102. Orr HT, Chung MY, Banfi S, Kwiatkowski TJ Jr, Servadio A, Beaudet AL et al (1993) Expansion of an unstable trinucleotide CAG repeat in spinocerebellar ataxia type 1 . Nat Genet 4(3):221-226

103. Pulst SM, Nechiporuk A, Nechiporuk T, Gispert S, Chen XN, Lopes-Cendes I et al (1996) Moderate expansion of a normally biallelic trinucleotide repeat in spinocerebellar ataxia type 2 . Nat Genet 14(3):269-276

104. Kawaguchi Y, Okamoto T, Taniwaki M, Aizawa M, Inoue M, Katayama $\mathrm{S}$ et al (1994) CAG expansions in a novel gene for Machado-Joseph disease at chromosome 14q32.1. Nat Genet 8(3):221-228

105. Flanigan K, Gardner K, Alderson K, Galster B, Otterud B, Leppert MF et al (1996) Autosomal dominant spinocerebellar ataxia with sensory axonal neuropathy (SCA4): clinical description and genetic localization to chromosome 16q22.1. Am J Hum Genet 59(2):392-399

106. Ranum LP, Schut LJ, Lundgren JK, Orr HT, Livingston DM (1994) Spinocerebellar ataxia type 5 in a family descended from the grandparents of President Lincoln maps to chromosome 11. Nat Genet 8(3):280-284

107. Zhuchenko O, Bailey J, Bonnen P, Ashizawa T, Stockton DW, Amos C et al (1997) Autosomal dominant cerebellar ataxia (SCA6) associated with small polyglutamine expansions in the alpha 1A-voltage-dependent calcium channel. Nat Genet 15(1):62-69

108. Trottier Y, Lutz Y, Stevanin G, Imbert G, Devys D, Cancel G et al (1995) Polyglutamine expansion as a pathological epitope in Huntington's disease and four dominant cerebellar ataxias. Nature 378(6555):403-406

109. Koob MD, Moseley ML, Schut LJ, Benzow KA, Bird TD, Day JW et al (1999) An untranslated CTG expansion causes a novel form of spinocerebellar ataxia (SCA8). Nat Genet 21(4):379-384

110. Matsuura T, Yamagata T, Burgess DL, Rasmussen A, Grewal RP, Watase K et al (2000) Large expansion of the ATTCT pentanucleotide repeat in spinocerebellar ataxia type 10. Nat Genet 26(2):191-194

111. Houlden H, Johnson J, Gardner-Thorpe C, Lashley T, Hernandez $\mathrm{D}$, Worth P et al (2007) Mutations in TTBK2, encoding a kinase implicated in tau phosphorylation, segregate with spinocerebellar ataxia type 11. Nat Genet 39(12):1434-1436

112. Waters MF, Minassian NA, Stevanin G, Figueroa KP, Bannister JP, Nolte D et al (2006) Mutations in voltage-gated potassium channel KCNC3 cause degenerative and developmental central nervous system phenotypes. Nat Genet 38(4):447-451

113. Brkanac Z, Bylenok L, Fernandez M, Matsushita M, Lipe H, Wolff J et al (2002) A new dominant spinocerebellar ataxia linked to chromosome 19q13.4-qter. Arch Neurol 59(8):1291-1295

114. van de Leemput J, Chandran J, Knight MA, Holtzclaw LA, Scholz S, Cookson MR et al (2007) Deletion at ITPR1 underlies ataxia in mice and spinocerebellar ataxia 15 in humans. PLoS Genet 3(6):e108

115. Miyoshi Y, Yamada T, Tanimura M, Taniwaki T, Arakawa K, Ohyagi $Y$ et al (2001) A novel autosomal dominant spinocerebellar ataxia (SCA16) linked to chromosome 8q22.1-24.1. Neurology $57(1): 96-100$

116. Koide R, Kobayashi S, Shimohata T, Ikeuchi T, Maruyama M, Saito M et al (1999) A neurological disease caused by an expanded CAG trinucleotide repeat in the TATA-binding protein gene: a new polyglutamine disease? Hum Mol Genet 8(11):2047-2053

117. Brkanac Z, Fernandez M, Matsushita M, Lipe H, Wolff J, Bird TD et al (2002) Autosomal dominant sensory/motor neuropathy with Ataxia (SMNA): Linkage to chromosome 7q22-q32. Am J Med Genet 114(4):450-457

118. Schelhaas HJ, Ippel PF, Hageman G, Sinke RJ, van der Laan EN, Beemer FA (2001) Clinical and genetic analysis of a fourgeneration family with a distinct autosomal dominant cerebellar ataxia. J Neurol 248(2):113-120

119. Knight MA, Gardner RJ, Bahlo M, Matsuura T, Dixon JA, Forrest SM et al (2004) Dominantly inherited ataxia and dysphonia with dentate calcification: spinocerebellar ataxia type 20 . Brain 127(Pt 5):1172-1181

120. Devos D, Schraen-Maschke S, Vuillaume I, Dujardin K, Naze P, Willoteaux $C$ et al (2001) Clinical features and genetic analysis of a new form of spinocerebellar ataxia. Neurology 56(2):234-238

121. Verbeek DS, van de Warrenburg BP, Wesseling P, Pearson PL, Kremer HP, Sinke RJ (2004) Mapping of the SCA23 locus involved in autosomal dominant cerebellar ataxia to chromosome region 20p13-12.3. Brain 127(Pt 11):2551-2557 
122. Stevanin G, Bouslam N, Thobois S, Azzedine H, Ravaux L, Boland A et al (2004) Spinocerebellar ataxia with sensory neuropathy (SCA25) maps to chromosome 2p. Ann Neurol 55(1):97-104

123. Yu GY, Howell MJ, Roller MJ, Xie TD, Gomez CM (2005) Spinocerebellar ataxia type 26 maps to chromosome 19p13.3 adjacent to SCA6. Ann Neurol 57(3):349-354

124. Svenstrup K, Nielsen TT, Aidt F, Rostgaard N, Duno M, Wibrand F et al (2017) SCA28: novel mutation in the AFG3L2 proteolytic domain causes a mild cerebellar syndrome with selective type-1 muscle fiber atrophy. Cerebellum 16(1):62-67

125. Dudding TE, Friend K, Schofield PW, Lee S, Wilkinson IA, Richards RI (2004) Autosomal dominant congenital nonprogressive ataxia overlaps with the SCA15 locus. Neurology 63(12):2288-2292

126. Storey E, Bahlo M, Fahey M, Sisson O, Lueck CJ, Gardner RJ (2009) A new dominantly inherited pure cerebellar ataxia, SCA 30. J Neurol Neurosurg Psychiatry 80(4):408-411

127. Nagaoka U, Takashima M, Ishikawa K, Yoshizawa K, Yoshizawa T, Ishikawa $\mathrm{M}$ et al (2000) A gene on SCA4 locus causes dominantly inherited pure cerebellar ataxia. Neurology 54(10):1971-1975

128. Cadieux-Dion M, Turcotte-Gauthier M, Noreau A, Martin C, Meloche C, Gravel M et al (2014) Expanding the clinical phenotype associated with ELOVL4 mutation: study of a large French-Canadian family with autosomal dominant spinocerebellar ataxia and erythrokeratodermia. JAMA Neurol 71(4):470-475

129. Wang JL, Yang X, Xia K, Hu ZM, Weng L, Jin X et al (2010) TGM6 identified as a novel causative gene of spinocerebellar ataxias using exome sequencing. Brain 133(Pt 12):3510-3518

130. Serrano-Munuera C, Corral-Juan M, Stevanin G, San Nicolas H, Roig C, Corral J et al (2013) New subtype of spinocerebellar ataxia with altered vertical eye movements mapping to chromosome 1p32. JAMA Neurol 70(6):764-771

131. Di Gregorio E, Borroni B, Giorgio E, Lacerenza D, Ferrero M, Lo Buono N et al (2014) ELOVL5 mutations cause spinocerebellar ataxia 38. Am J Hum Genet 95(2):209-217

132. Koide R, Ikeuchi T, Onodera O, Tanaka H, Igarashi S, Endo K et al (1994) Unstable expansion of CAG repeat in hereditary dentatorubral-pallidoluysian atrophy (DRPLA). Nat Genet 6(1):9-13

133. Klein CJ, Botuyan MV, Wu Y, Ward CJ, Nicholson GA, Hammans $S$ et al (2011) Mutations in DNMT1 cause hereditary sensory neuropathy with dementia and hearing loss. Nat Genet 43(6):595-600 